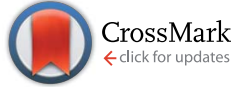

Cite this: RSC Adv., 2016, 6, 40058

Received 9th February 2016

Accepted 14th April 2016

DOI: $10.1039 / c 6 r a 03664 c$

www.rsc.org/advances

\section{Biocompatible polydopamine-like particles for the removal of heavy metals at extremely low concentrations}

\author{
Ada Rebeca Contreras Rodríguez, ${ }^{a}$ Javier Saiz-Poseu, ${ }^{\text {b }}$ Javier García-Pardo, ${ }^{c}$ \\ Beatriz García, ${ }^{\text {b Julia Lorenzo, }}$ Isaac Ojea-Jiménez, ${ }^{\mathrm{b}}$ Dimitrios Komilis, ${ }^{a}$ Josep Sedó, ${ }^{\mathrm{b}}$ \\ Felix Busqué, ${ }^{d}$ Antoni Sánchez, ${ }^{\text {*a }}$ Daniel Ruiz-Molina ${ }^{b}$ and Xavier Font ${ }^{a}$
}

\begin{abstract}
A family of catechol-based submicron particles, with sizes between 200 and $300 \mathrm{~nm}$, was tested for the removal of $\mathrm{Cd}(\|), \mathrm{Pb}(॥)$ and $\mathrm{Cr}(\mathrm{VI})$ in water. The highest adsorption capacity was obtained with catecholbased particles in the case of $\mathrm{Pb}(॥)$, followed by $\mathrm{Cd}(॥)$. However, the catechol particles failed to adsorb $\mathrm{Cr}(\mathrm{VI})$. Our results indicate an up to four-fold increase of the adsorption capacity of these particles compared to that of activated carbon under the same experimental conditions. To check the biocompatible character of the submicron particles, their stability was evaluated in a phosphate buffer solution (PBS) and in a cell culture medium. The results confirmed that the presence of proteins in the medium favors their stability. A bioluminescent Vibrio fischeri test and a cytotoxicity assay on the HepG2 cell line were used to determine that the catechol particles did not exhibit any substantial toxicity. The results show that these catechol-based particles can be used as an efficient biocompatible adsorbent to remove heavy metals at extremely low concentrations.
\end{abstract}

\section{Introduction}

Environmental contamination caused by heavy metals is mainly due to human activities such as mining, alloy manufacturing, metal finishing, water cooling systems and welding, among others. These processes produce non-treated effluents that can contaminate aquatic systems. Water pollution by heavy metals is a major concern worldwide since these pollutants can only be immobilized and not metabolized or decomposed. Thus, this can cause accumulation in the environment or living systems producing serious human health problems. ${ }^{1,2}$ Therefore, the heavy metals limits set by the World Health Organization for drinking water are extremely low due to the toxic and bioaccumulative effects of these compounds. ${ }^{3}$ For example, the maximum limit for cadmium is $0.003 \mathrm{mg} \mathrm{L}^{-1}, 0.01 \mathrm{mg} \mathrm{L}^{-1}$ for lead and $0.05 \mathrm{mg}^{-1}$ for total chromium. Because of these concerns, a great effort is made to develop low cost processes to effectively remove heavy metal ions from drinking water.

\footnotetext{
${ }^{a}$ Department of Chemical Engineering, Escola d'Enginyeria, Universitat Autònoma de Barcelona, 08193 Bellaterra, Spain. E-mail: antoni.sanchez@uab.cat; Fax: +34935812013; Tel: +34-935811019

${ }^{b}$ Catalan Institute of Nanoscience and Nanotechnology (ICN2), CSIC and The Barcelona Institute of Science and Technology, Campus UAB, Bellaterra, 08193 Barcelona, Spain

${ }^{c}$ Institut de Biotecnologia $i$ de Biomedicina and Departament de Bioquímica $i$ de Biologia Molecular, Universitat Autònoma de Barcelona, Bellaterra, Barcelona, Spain ${ }^{d}$ Department of Chemistry, Universitat Autònoma de Barcelona, 08193 Bellaterra, Spain
}

For the removal and separation of heavy metals from drinking water, several technologies exist, such as chemical precipitation, adsorption, ion exchange, solvent extraction, oxidation and reduction. Adsorption is considered effective and is widely applied due to its simplicity and ease of operation. ${ }^{4} \mathrm{~A}$ significant number of new low-cost adsorbents have been used for the removal of metals with variable adsorption capacities. For example, activated carbon derived from bagasse (27.49$\left.49.07 \mathrm{mg} \mathrm{g}^{-1}\right)^{5}$ and chitin $\left(14.7 \mathrm{mg} \mathrm{g}^{-1}\right)^{6}$ have been used for the removal of $\mathrm{Cd}(\mathrm{II})$; coconut fibers $\left(4.38 \mathrm{mg} \mathrm{g}^{-1}\right)^{5}$ and iron nanoparticles $\left(82.64 \mathrm{mg} \mathrm{g}^{-1}\right)^{7}$ have been used for the removal of $\mathrm{Pb}(\mathrm{II})$, and maghemite $\left(19.2 \mathrm{mg} \mathrm{g}^{-1}\right)^{8}$ and EA-200 activated carbon $\left(10 \mathrm{mg} \mathrm{g}^{-1}\right)^{9}$ have been used for the removal of $\mathrm{Cr}(\mathrm{vI})$. Recent advances also suggest that the adsorption of heavy metals using nanotechnology devices could improve or greatly ameliorate the challenge of improving drinking water quality. ${ }^{7,9,10}$ Submicron particles have two key properties that make them particularly attractive as adsorbents: (I) they have much larger surface areas than bulk particles on a mass basis, and (II) they can be also functionalized to increase their affinity to specific compounds, such as metal ions. ${ }^{10}$ Therefore, this approach turns out to be especially efficient for the removal of low concentration pollutants. In this regard, the fabrication of novel nanostructures, with simple and environmentally friendly compositions, that can effectively remove pollutants is highly desirable.

In the last years, nature has inspired the design and development of novel functional nanoparticles with removal and 
separation capacities for heavy metals. One example of this fruitful approach has been the fabrication of polydopamine (PDA) materials. ${ }^{\mathbf{1 1}}$ PDA (a catecholic compound) is a novel bioinspired material based on the catechol moiety, the presence of which on mussel byssus proteins is essential to their critical adhesive function in wet environments. ${ }^{12}$ For metal adsorption applications, the catechol groups and nitrogen heteroatoms in PDA structures have also had a strong tendency to interact with positively charged metal ion species. ${ }^{13}$ Therefore, by combining both the adhesive properties of the PDA structures and the metal binding capacities, different nanostructures have been coated with PDA to study metal removal. One of the first materials that was studied with this aim was graphene. ${ }^{\mathbf{1 4}}$ For instance, benefiting from the abundant functional groups of polydopamine and the high specific surface areas of graphene, hydrogels with three-dimensional interconnected pores have been fabricated and were shown to exhibit high adsorption capacities with respect to heavy metal ions. ${ }^{15}$ PDA-coated graphene oxide (GO) composites for effectively decontaminating wastewater from heavy metal ions have been also reported. ${ }^{\mathbf{1 6}}$ PDA-GO exhibited an improved adsorption capacity for heavy metal ions of $53.6 \mathrm{mg} \mathrm{g}^{-1}$ for $\mathrm{Pb}(\mathrm{II}), 24.4 \mathrm{mg} \mathrm{g}^{-1}$ for $\mathrm{Cu}(\mathrm{II}), 33.3$ $\mathrm{mg} \mathrm{g}^{-1}$ for $\mathrm{Cd}(\mathrm{II})$ and $15.2 \mathrm{mg} \mathrm{g}^{-1}$ for $\mathrm{Hg}$ (II).$^{\mathbf{1 6}}$ In addition, PDAdecorated magnetic nanoparticles have been used for the removal of mixtures of heavy metals including $\mathrm{Cu}(\mathrm{II}), \mathrm{Ag}$ (I) and $\mathrm{Hg}(\mathrm{II}) \cdot{ }^{17-19}$

Despite its versatility and simplicity, PDA fabrication cannot be accurately controlled and exhibits a remarkable insolubility, being restricted by in situ polymerization methodologies. Recently, we have reported a new experimental approach for the preparation of PDA-related submicron particles derived from the polymerization of the amphiphile 4-heptadecylcatechol with ammonia. ${ }^{20}$ Overall, the strategy reported combines advantages, such as ease of preparation, solubility in appropriate solvents and improved surface functionalization. Likewise, the assynthesized material was shown to spontaneously form particles (catechol-based) with a diameter of a few hundred nanometers in water.

The aim of this study is to explore the capacity of this new family of catechol-based particles to adsorb $\mathrm{Cd}(\mathrm{II}), \mathrm{Pb}$ (II) and $\mathrm{Cr}(\mathrm{vI})$ dissolved in water at very low concentration. Activated carbon was also used, under the same experimental conditions, as a reference adsorbent. In both cases, a factorial experimental design was adopted to mathematically describe adsorption capacity as a function of the heavy metal concentration and the adsorbent concentration. A bioluminescent bacteria test and a cytotoxicity assay were also carried out to assess the toxicity of the reported particles.

\section{Materials and methods}

\subsection{Synthesis of catechol-based}

The synthesis of catechol-based submicron particles has been reported elsewhere. ${ }^{13}$ A brief description is provided: a large excess of aqueous ammonia (100:1) was slowly added under vigorous stirring and under the presence of air to a solution of 4heptadecylcatechol $(0.2 \%, \mathrm{w} / \mathrm{v})$ in methanol at $40{ }^{\circ} \mathrm{C}$. The reaction was complete in 24 hours. Interestingly, the morphological characterization by SEM and TEM obtained from the (polar) reaction medium upon evaporation of the ammonia excess revealed the formation of solid particles with diameters ranging from 100 to $350 \mathrm{~nm}$ (observed directly from SEM images) or an average diameter of $301 \mathrm{~nm}$ (PDI: 0.145) as obtained by DLS measurements.

\subsection{Scanning electron microscopy (SEM)}

SEM measurements were carried out with a HITACHI S-570 and a QUANTA FEI 200 FEG-ESEM, both operating at $15 \mathrm{kV}$. Samples for the observation of catechol particles were prepared by casting a drop of the corresponding dispersion on aluminum tape and by further evaporation of the solvent at room temperature. Prior to observation with SEM, all samples were metalized with a thin layer of gold using a sputter coater K550 (Emitech).

\subsection{Adsorption experiments}

The heavy metals solutions were prepared from cadmium nitrate tetrahydrate (Sigma-Aldrich), lead(II) nitrate (SigmaAldrich) and potassium dichromate (Panreac). The activated carbon (Merck, ref. no. 1021860250) that was used had a particle diameter of $<100 \mu \mathrm{m}$. This activated carbon is of high performance and it is typically used for adsorption in drinking water purification. All the experiments were carried out at room temperature and at $\mathrm{pH}$ 7. The adsorption equilibrium was considered to be reached at $24 \mathrm{~h}$ for all cases. ${ }^{\mathbf{7 , 9 2}}$ The mixture was then centrifuged (10 $000 \mathrm{rpm}$ for $10 \mathrm{~min}$ ) and filtered (0.22 $\mu \mathrm{m})$ to separate the catechol-based particles from the solution. The supernatant was analyzed for the residual dissolved cadmium(II), lead(II) and chromium(VI). The determination of cadmium, lead and chromium was performed by a mass spectrometer (ICP-MS) Agilent, model 7500ce. The adsorption capacity at the equilibrium was calculated with the following equation:

$$
q=\left(C_{0}-C_{\mathrm{e}}\right) V / m
$$

where $C_{0}$ and $C_{\mathrm{e}}$ are the initial and equilibrium concentrations of the heavy metal $\left(\mathrm{mg} \mathrm{L}^{-1}\right)$ respectively, $V$ is the volume (L) and $m(\mathrm{~g})$ is the mass of the catechol particles.

\subsection{Experimental design}

In a factorial experimental design, all possible combinations between factors at all levels are investigated ${ }^{22}$ in order to estimate the effects of the main factors (concentrations of metal and catechol) and of the (likely) interactions. This procedure can provide valid conclusions for a range of experimental conditions and permits a statistical validation of the results obtained..$^{23}$ In this work, a three-level and two-factor full factorial design was employed that contained all the possible combinations between the two factors $(f=2)$ and their three levels $(L=3)$, resulting in $N=L^{f}=9$ experiments with one central point replicated three times. ${ }^{24}$ As a result, twelve experiments were performed as shown in Tables 1 and 2, where 
Table 1 Experimental design matrix used for the single metal adsorption experiments of $\mathrm{Cd}(॥)$ and $\mathrm{Pb}(॥)$ with catechol-based particles ${ }^{b}$

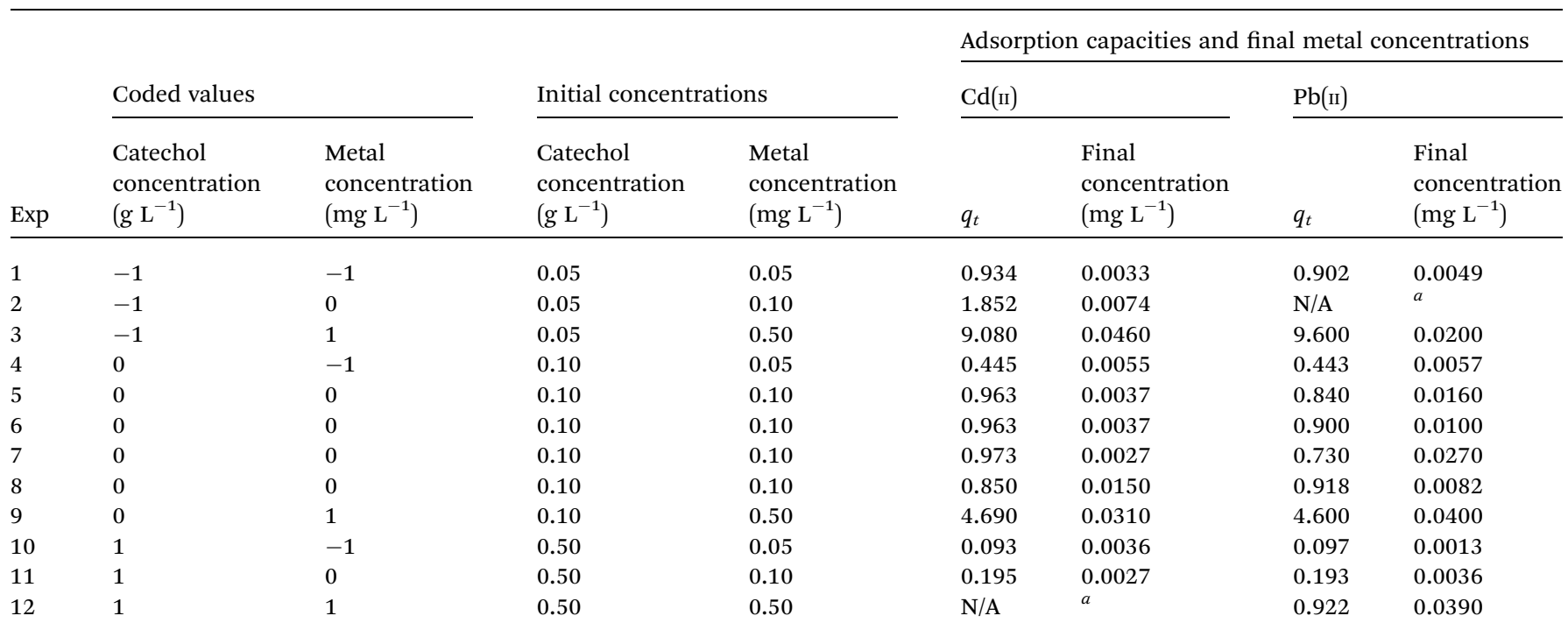

${ }^{a}$ Below detection limit. ${ }^{b} q_{t}$ : adsorption capacity measured after $24 \mathrm{~h}$ and expressed in mg metal per g catechol; N/A: not available.

Table 2 Experimental design matrix used for the single metal adsorption experiments of $\mathrm{Cd}(॥), \mathrm{Pb}(॥)$ and $\mathrm{Cr}(\mathrm{VI})$ with activated carbon ${ }^{b}$

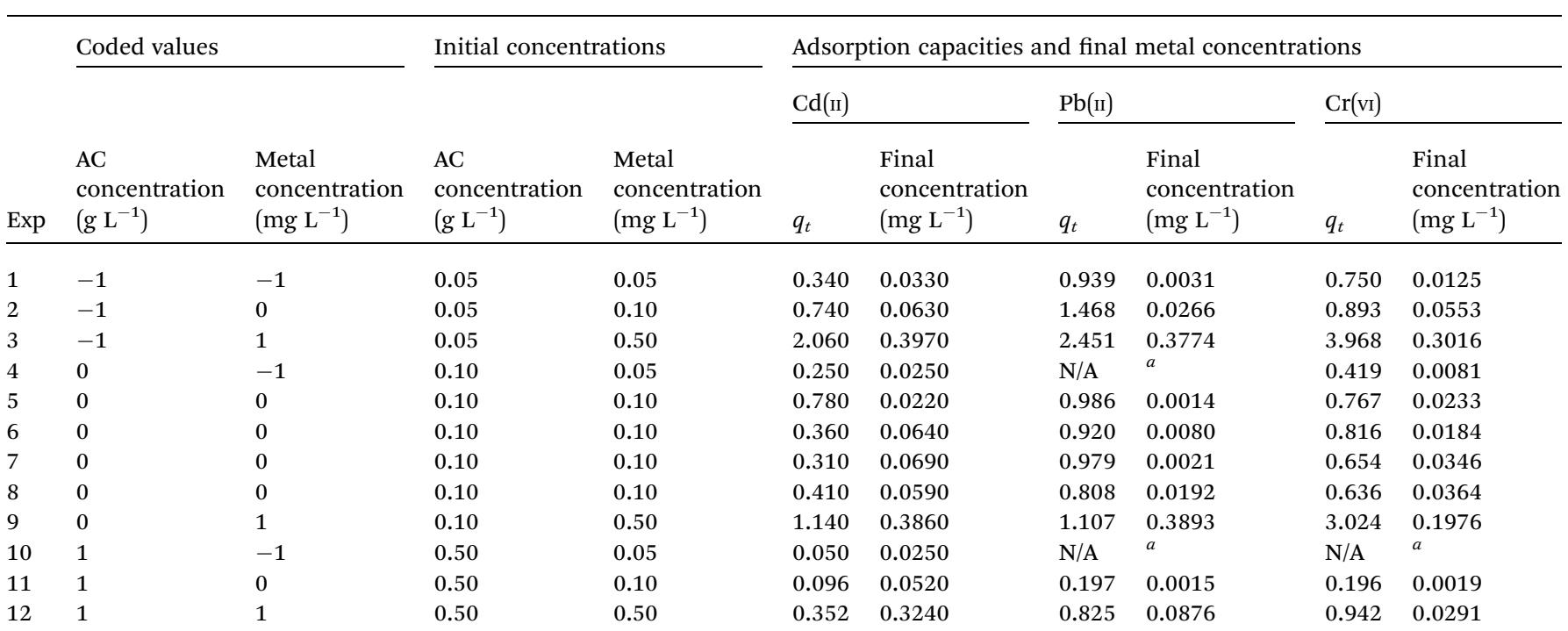

${ }^{a}$ Below detection limit. ${ }^{b} q_{t}$ : adsorption capacity measured after $24 \mathrm{~h}$ and expressed in mg metal per g AC; AC: activated carbon; N/A: not available.

the coded values represent the levels of each factor (i.e. lowest level (-1), center point (0), highest level (1)). The lowest level for the initial metal concentrations was set in order to be associated with the maximum concentration of heavy metals allowed in drinking water, while initial dose of adsorbent were established based on literature. ${ }^{15}$

\subsection{Regression modeling}

The regression started with a full polynomial model and terms were sequentially removed in order to obtain the best reduced model (BRM), with the fewest possible statistically significant terms (at $p<0.05$ ), that can still adequately describe the data. ${ }^{25}$
The initial quadratic equation (eqn (2)) that was used to fit the experimental data was:

$$
Y=b_{0}+b_{1} X_{1}+b_{2} X_{2}+b_{3} X_{1}^{2}+b_{4} X_{2}^{2}+b_{5} X_{1} X_{2}
$$

where: $b_{0}, b_{1} \ldots b_{5}$ are the model coefficients, $X_{1}$ represents the concentration of the adsorbent $\left(\mathrm{g} \mathrm{L}^{-1}\right), X_{2}$ represents the initial concentration of the heavy metal $\left(\mathrm{mg} \mathrm{L}^{-1}\right)$ and $Y\left(q_{t}\right)$ is the dependent variable, namely the adsorption capacity of each adsorbent ( $\mathrm{mg}$ metal per $\mathrm{g}$ adsorbent). The statistical analysis was performed with MatLab (version 2011b, Mathworks). 


\subsection{Analytical methods}

Prior to metal analysis, all samples were acidified with concentrated $\mathrm{HNO}_{3}$, to a final $1 \%$ concentration, so that to obtain a $\mathrm{pH}<$ 3. The determination of cadmium, lead and chromium was performed by a mass spectrometer (ICP-MS) Agilent, model 7500ce.

\subsection{Bioluminescent test}

Measurements based on microorganisms are fast, cost effective, reproducible and are becoming increasingly common to study toxicity. ${ }^{26}$ The method used in this study is based on the determination of the inhibition of the luminescence produced by marine bacteria (Vibrio fischeri). The assay consists of serial dilutions that mix the pollutant and a suspension of luminescent bacteria in a cuvette; the reduction of the light emitted is directly related to the relative toxicity of the sample. ${ }^{27}$ Toxicity values can be expressed as $\mathrm{EC}_{50}$ (half maximal effective concentration), which is a measure of the effectiveness of a compound in inhibiting biological or biochemical functions. It is obtained after plotting the percentage of luminescence reduction against the concentration after 5 and $15 \mathrm{~min}$ incubation times. Depending on $\mathrm{EC}_{50}$ values samples are classified as highly toxic $\left(\mathrm{EC}_{50} \leq 25\right)$, moderately toxic $(25-50 \%)$, toxic (51-74\%), slightly toxic (76-100\%) or non-toxic ( $\geq 100 \%) \cdot{ }^{7,28} \mathrm{~A}$ commercial Microtox® model 500 analyzer (Azur Environmental, Berkshire, UK) was used. The $81.9 \%$ basic test protocol was used to determine the toxicity for the initial solutions of cadmium and lead $\left(0.5 \mathrm{mg} \mathrm{L}^{-1}\right)$, for the initial suspensions of catechol $\left(0.1 \mathrm{~g} \mathrm{~L}^{-1}\right)$ and also for the final suspension obtained from the adsorption process (heavy metal plus catechol). No visible precipitate or agglomeration was observed during the tests. Toxicity tests were all performed in triplicate.

\subsection{Stability assays}

The solubility and stability of catechol particles were investigated in several buffers in order to mimic different biological conditions. Dilutions of catechol particles were prepared at a concentration of $1 \mathrm{mg} \mathrm{mL} \mathrm{m}^{-1}$ in: Milli-Q purified water, phosphate saline buffer (PBS) (Invitrogen, Inc.) and Modified Eagle's Medium (MEM) (Invitrogen, Inc.) with and without the addition of $50 \mu \mathrm{g} \mathrm{mL}^{-1}$ Bovine Serum Albumin (BSA) or 10\% (v/v) fetal bovine serum (FBS) respectively. Samples were incubated for $72 \mathrm{~h}$ at $37^{\circ} \mathrm{C}$.

\subsection{Protein binding assays}

The binding of catechol particles to proteins was investigated by the tryptophan fluorescence of bovine serum albumin (BSA). Tryptophan fluorescence emission spectrum was measured in a Jasco FP-8200 spectrofluorimeter using and excitation wavelength of $275 \mathrm{~nm}$ and collecting the emission spectra between 290 and $450 \mathrm{~nm}$. Slit widths were typically $5 \mathrm{~nm}$ for the excitation and $5 \mathrm{~nm}$ for emission and the spectra were acquired at 0.5

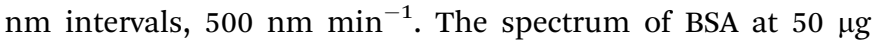
$\mathrm{mL}^{-1}$ in $50 \mathrm{mM}$ sodium phosphate buffer $(\mathrm{pH} 7.4)$ was acquired in absence and in the presence of catechol particles at $25 \mu \mathrm{g}$ $\mathrm{mL}^{-1}, 50 \mu \mathrm{g} \mathrm{mL}^{-1}$ and $100 \mu \mathrm{g} \mathrm{mL}^{-1}$. The spectrum of the buffer with $100 \mu \mathrm{g} \mathrm{mL} \mathrm{m}^{-1}$ catechol particles alone was used as control.

\subsection{Cytotoxicity assays}

The cytotoxicity assays were performed using human hepatoma cells (HepG2) (ATCC HB-8065). The cells were grown in Modified Eagle's Medium (MEM) alpha supplemented with $10 \%$ (v/v) heat inactivated fetal bovine serum (FBS) in a highly humidified atmosphere of $95 \%$ air with $5 \% \mathrm{CO}_{2}$ at $37{ }^{\circ} \mathrm{C}$. The cytotoxicity of catechol-based particles on HepG2 cells was measured using the XTT assay based on the determination of the ability of living cells to reduce 2,3-bis-(2-methoxy-4-nitro-5-sulfophenyl)-2 $\mathrm{H}$ tetrazolium-5-carboxanilide (XTT) to formazan. ${ }^{29,30}$ To perform the experiments, cells were seeded into 96-well plates at a cell density of $4.0 \times 10^{3}$ cells per well and growth for $24 \mathrm{~h}$ for complete cell adhesion. Then, catechol particles were added at different concentrations (from $1 \mu \mathrm{g} \mathrm{mL} \mathrm{m}^{-1}$ to $1000 \mu \mathrm{g} \mathrm{mL}{ }^{-1}$ ) and incubated for $24 \mathrm{~h}$. After incubation, $20 \mu \mathrm{L}$ of the XTT solution was added to each well. The color formed after $3 \mathrm{~h}$ incubation at $37{ }^{\circ} \mathrm{C}$ was quantified by a spectrophotometric plate reader (Perkin Elmer Victor3 V) at a $490 \mathrm{~nm}$ wavelength. Cell cytotoxicity was evaluated in terms of cell-growth inhibition in treated cultures and expressed as a \% of the control conditions.

\section{Results and discussion}

\subsection{Submicron catechol particles characterization and adsorption results}

The morphological characterization by SEM of the material directly obtained from the reaction medium showed that the formed solid particles had diameters between 200 and $350 \mathrm{~nm}$ (Fig. 1a and b). Full information about the catechol structure and properties can be found elsewhere. ${ }^{12}$ The surface charge of the particles solution (measured as zeta potential) was around $-45 \mathrm{mV}$ at $\mathrm{pH} \approx 7$, which is in agreement with the presence of a certain amount of polyphenol groups in the outermost layer that achieves a stable colloidal suspension for many days. Fig. 1c shows the morphology of the same particles after exposure to the heavy metal ions solution (vide infra). As can be seen, the catechol particles undergoing this treatment retain their overall dimensions. However, it can be observed that, in some cases, the particles tend to fuse together mediated by the action of the metal ions.

The achieved adsorption capacities of the three metals in a single component system onto the catechol-based particles and onto the activated carbon are included in Tables 1 and 2, respectively. In the adsorption experiments with catechol-based particles, it was observed that only the solutions of cadmium(II) and lead(II) showed changes in concentration, whereas the chromium(vi) solution remained constant under all conditions. The lack of affinity to chromium is attributed to repulsive forces between the surface negatively charged of the particles and the negative charge of the dichromate anion. The speciation of heavy metals also plays an important role in the adsorption process. One parameter that has been pointed out by several authors is the $\mathrm{pH}^{, 35-38}$ which affects metal speciation, and, depending on its variability, can favor or not the sorption of metal complexes. The highest adsorption capacities $\left(q_{t}\right)$ obtained for lead (9.60 mg $\mathrm{Pb}$ (II) per g particle) and cadmium (9.08 


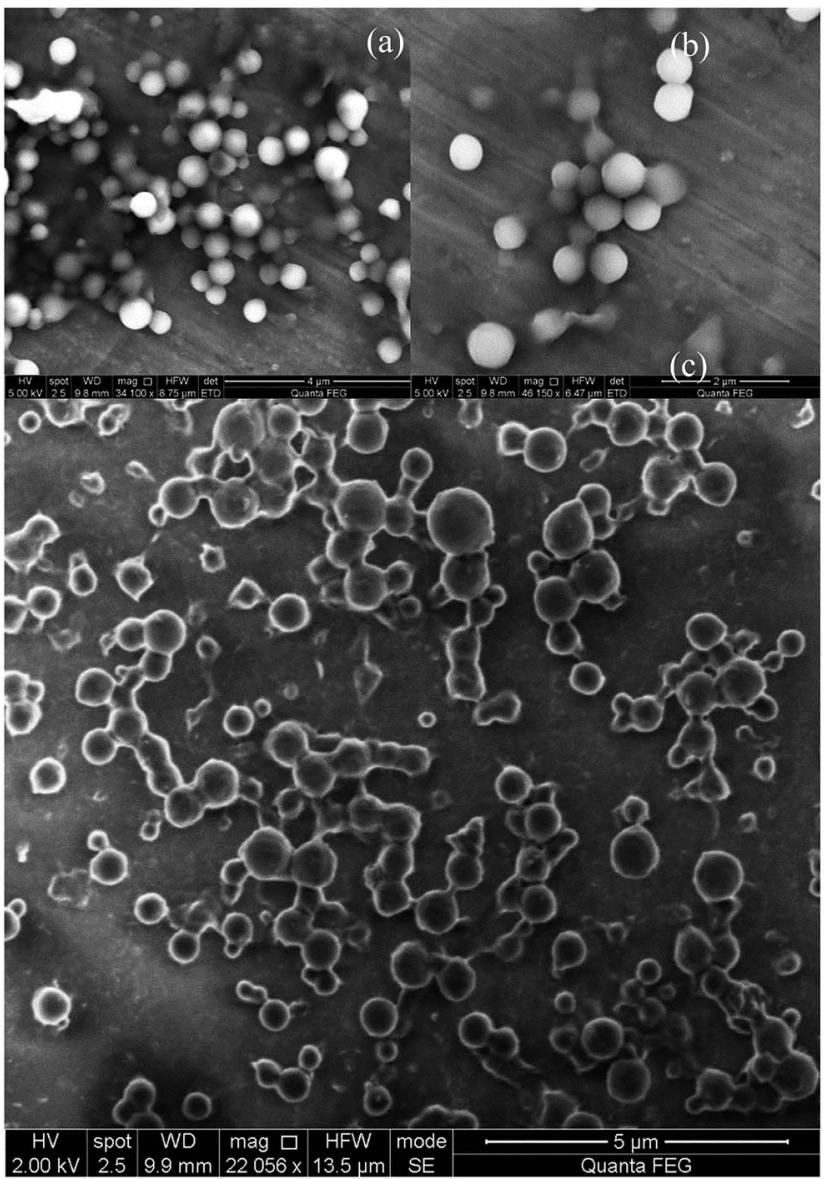

Fig. 1 SEM images of the synthesized catechol particles: (a) and (b) particles ranging from 200 to $350 \mathrm{~nm}$, (c) particles morphology after exposure to the heavy metal ions solution.

mg Cd(II) per g particle) were similar. Has been suggested that the adsorption process of heavy metal ions is mainly based on electrostatic interactions, therefore it is expected that the metal ion bonding was related to many functional groups in the catechol-based particles including, carboxyl and amino groups. ${ }^{13,15}$

Table 1 also shows that the adsorption capacity increased with an increase of the initial concentration of the metal and with a reduction of the concentration of catechol particles.

The highest adsorption capacities obtained with activated carbon (Table 2) for cadmium (2.06 mg Cd(II) per $\mathrm{g}$ carbon activated) and lead (2.46 $\mathrm{mg} \mathrm{Cd}(\mathrm{II})$ per $\mathrm{g}$ carbon activated) were lower than those obtained with catechol. In the case of activated carbon, only chromium(vi) observed a higher adsorption capacity (3.96 $\mathrm{mg} \mathrm{Cr}(\mathrm{vI})$ per $\mathrm{g}$ activated carbon) compared to that in catechol particles. Based on Tables 1 and 2, the highest adsorption capacities were obtained at the lowest concentrations of adsorbent and at the highest metal concentrations. The differences existing in the adsorption capacities of the different metals may be attributed to the specific properties of activated carbon, such as porosity (micropore volume, micropore size and distribution, etc.), chemical nature of the activated surface or the activation process (chemical, physical). ${ }^{39}$ Other studies have found similar adsorption capacities with bituminous coal (8.89 mg $\mathrm{Pb}$ (II) per g) ${ }^{31}$ or with furnace sludge (7.39 mg Cd(II) per g) ${ }^{32}$ or even lower (3.27 $\mathrm{mg}$ Cd(II) per $\mathrm{g}$ ) with peach stone carbon. ${ }^{33}$ Other works, have found higher adsorption capacities $(93.2 \mathrm{mg}$ Cd(II) per g) using coconut coirpith, ${ }^{34}$ but in this case the concentration of metals was high and different from the intention of our study to remove heavy metals at extremely low concentrations.

According to Tables 1 and 2 and the initial values of heavy metal concentration, the mean metal removal percentages when catechol-based particles were used as adsorbents were $94 \%$ for $\mathrm{Cd}^{2+}$ and $91 \%$ for $\mathrm{Pb}^{2+}$. These removal percentages were up to around two times higher than those recorded for activated carbon (i.e. $40 \%$ for $\mathrm{Cd}^{2+}, 80 \%$ for $\mathrm{Pb}^{2+}$ and $73 \%$ for $\mathrm{Cr}^{6+}$ ), which also indicates the higher affinity between catechol-based particles and metals compared to activated carbon.

The adsorption capacities of activated carbon were in the same order of magnitude to those obtained with activated carbon derived from coconut shells $(1.4 \mathrm{mg} \mathrm{Cr}(\mathrm{vI}) \text { per } \mathrm{g})^{\mathbf{4 0}}$ and almond-shell carbon (1103 $\mathrm{m}^{2} \mathrm{~g}^{-1} ; 2.7 \mathrm{mg} \mathrm{Cd}(\mathrm{II})$ per g) ${ }^{\mathbf{4 1 , 4 2}}$ On the other hand, activated carbon prepared from apricot stone $\left(566 \mathrm{~m}^{2} \mathrm{~g}^{-1}\right)$ presented much higher adsorption capacities for these 3 metals (33.57 mg Cd(II) per g, $22.85 \mathrm{mg} \mathrm{Pb(II)} \mathrm{per} \mathrm{g,} \mathrm{29.47}$ $\mathrm{mg} \mathrm{Cr}(\mathrm{vI})$ per $\mathrm{g}){ }^{43}$ This variability is attributed to the variable surface properties of the sorbents as well as the ionic strength and solubility of the heavy metals, among other properties already mentioned. ${ }^{40}$ Additionally, a point of high interest would be to study the performance of catechol-based particles in multi-component systems, as we have obtained very promising results using model inorganic nanoparticles. ${ }^{44}$

A priori, catechol particles can be re-used upon treatment with acidic media; such treatment induces removal of metal ions by protonation of the catechol/phenol groups and isolation of the particles (for instance by centrifugation) from the metalcontaining solution. Moreover, such protonation is reversible as long as further exposure to basic media is prompted to deprotonate back the catechol/phenol groups recovering the chelating properties. However, some irreversibility of the process is found after each cycle as long protonation of the particles induces its flocculation in a reversible manner; i.e. some part of the product is not recovered after each cycle due to flocculation and precipitation processes.

\subsection{Empirical modeling to describe adsorption capacity}

Based on the model building methodology described in section 2.5 , the initial heavy metal concentration $\left(X_{2}\right)$ was found to be the only statistically significant (at $p<0.05$ ) variable to describe adsorption capacity. The BRM calculated is shown by eqn (3).

$$
Y=b_{2} X_{2}
$$

The coefficient associated to $X_{2}$ and the $p$-values for each system are presented in Table 3 . This finding indicates that the maximum adsorptive capacity of both sorbents has not been reached due to the low metal concentration range used in this study. The intercept was not included in the model since it did not have a physical meaning. 
Table 3 Empirical modeling results to describe the adsorption capacity of the catechol-based particles and of the activated carbon

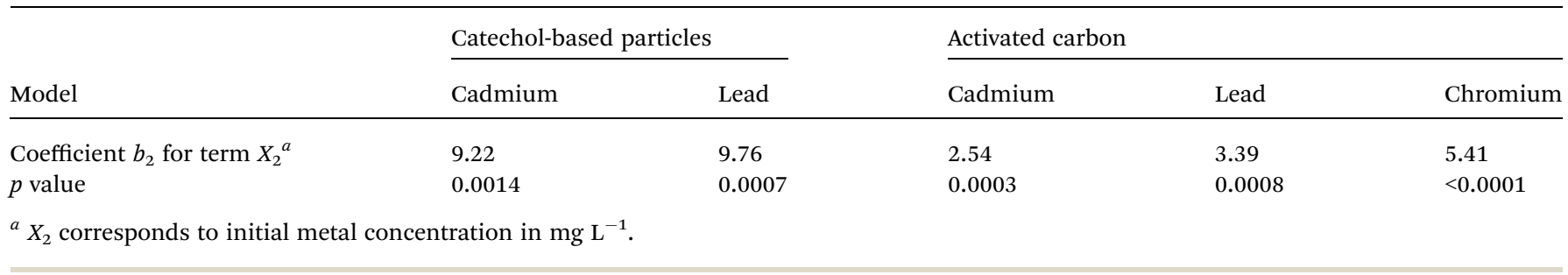

(a)

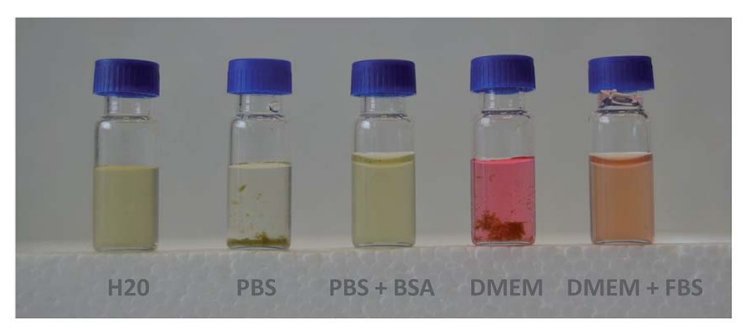

(b)

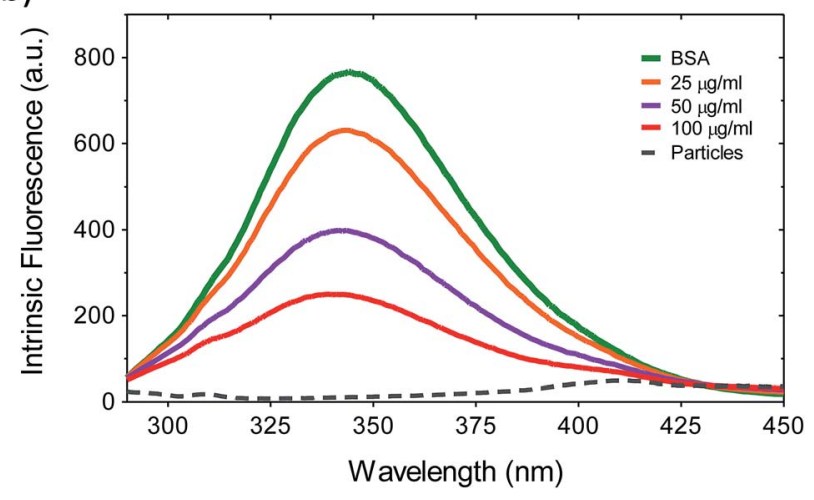

Fig. 2 (a) Images of catechol particles re-suspended at $1 \mathrm{mg} \mathrm{mL}^{-1}$ in water, phosphate buffered saline (PBS) and Modified Eagle's Medium (MEM) alpha and incubated for $72 \mathrm{~h}$ at $37^{\circ} \mathrm{C}$. (b) Tryptophan fluorescence spectra of BSA in absence (solid green line) and presence of 25 $\mu \mathrm{g} \mathrm{mL}^{-1}$ (solid orange line), $50 \mu \mathrm{g} \mathrm{mL}^{-1}$ (solid purple line) and $100 \mu \mathrm{g}$ $\mathrm{mL}^{-1}$ (solid red line) catechol particles. Particles bind to BSA triggering a concentration-dependent decrease of the intrinsic BSA tryptophan fluorescence.

\subsection{Stability assay}

The stability of catechol-based particles was evaluated in phosphate saline buffer (PBS), in PBS plus Bovine Serum Albumin (BSA) $50 \mu \mathrm{g} \mathrm{mL}{ }^{-1}$ and in Modified Eagle's Medium (MEM) cell culture medium (with or without fetal bovine serum) buffers after $72 \mathrm{~h}$ incubation to mimic a physiological environment. The objective was to study possible aggregation phenomena in biological environments, such as blood or tissues, which could affect their persistence of catechol particles once entering the human body.

Fig. 2a shows catechol particles aggregates in PBS or in MEM without FBS after $72 \mathrm{~h}$ incubation at $37^{\circ} \mathrm{C}$. The addition of FBS to the cell culture media (MEM + FBS) and BSA in the PBS (PBS + BSA) buffer improved the solubility and protected particles from aggregation. Therefore, this increased the stability of the unmodified particles due to nonspecific protein adsorption.
One of the major biological functions of albumins is their ability to carry drugs as well as endogenous and exogenous substances. Serum albumins are the most abundant proteins in plasma. As the major soluble protein constituents of the circulatory system, they have many physiological functions. ${ }^{45}$ BSA contains 582 amino acid residues with a molecular weight of 69000 , and two tryptophan moieties at positions 134 and 212 as well as tyrosine and phenylalanine. ${ }^{46}$ Conformational changes in BSA may disturb the microenvironment around the Trp residues and thus influence the fluorescence. As shown in Fig. 2b, the value of Trp fluorescence decreased as the concentration of particles increased; this suggests that the polarity of the microenvironment around the Trp residues increased because of the conformational changes of BSA at the tertiary structure level. ${ }^{47}$ Herein, we suggest that the adsorption of BSA on the catechol particles forces the BSA molecules to transform into a less compact structure, which allows the solvent to penetrate into the hydrophobic cavity of BSA, which increases the polarity of the microenvironment around Trp-212.

\subsection{Bioluminescent tests}

To determine the cytotoxicity of catechol-based particles for aquatic organisms, the initial sample, the sample after 24 hours of adsorption and the catechol particles without sorbed metals were tested using bioluminescence inhibition (Vibrio fischeri) tests. The results show that the catechol-based particles do not present a toxic effect before or after mixing them with heavy metals, and remained without showing toxicity effects throughout the adsorption process. This is important, as sometimes particles are very effective adsorbents, but present toxicity on aquatic environments. Some metal-oxide nanoparticles have been studied in this way. For example, $\mathrm{TiO}_{2}$ absorbs considerable UV radiation, yielding in aqueous media, hydroxyl species that may cause substantial damage to DNA. ${ }^{48}$ Other studies found that $\mathrm{Al}_{2} \mathrm{O}_{3}$, $\mathrm{Zn}$ and $\mathrm{ZnO}$ nanoparticles could reduce root growth due to perturbation of the soil microbial flora. ${ }^{28,49}$

\subsection{Cytotoxicity of catechol particles in cells}

Finally, to clarify if catechol-based particles display any kind of cytotoxicity towards human cells, they were tested against the hepatic cell line HepG2. The XTT assay was used to assess cell viability and is based on the reduction potential of metabolically active cells. After $24 \mathrm{~h}$, no significant signs of toxicity were observed for a broad range from 25 to $1000 \mu \mathrm{gL}^{-1}$ of catechol 
(a)

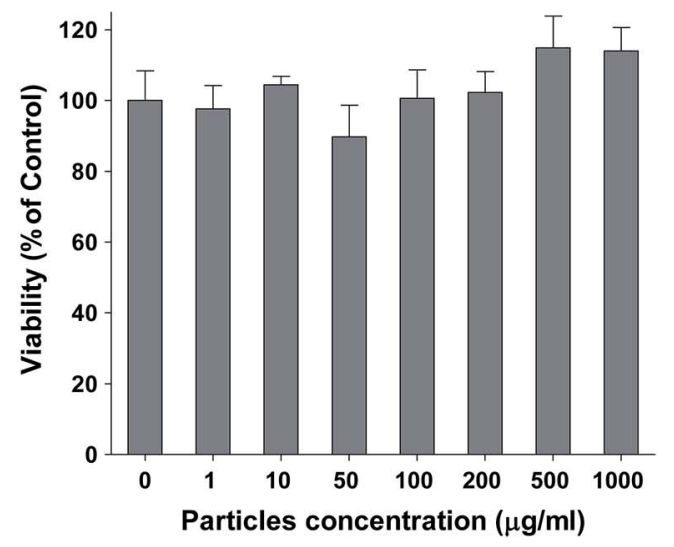

(b)

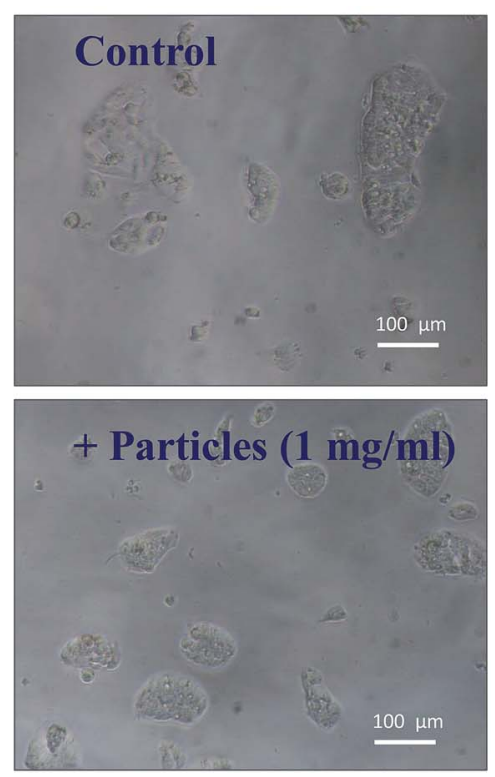

Fig. 3 Cytotoxicity of catechol particles. (a) Cytotoxicity of catechol particles was evaluated against a liver hepatocellular carcinoma cell line (HepG2) by the XTT assay. Cells were incubated for 24 in absence and in presence of five increasing concentrations of catechol particles (up to $1000 \mu \mathrm{g} \mathrm{mL}^{-1}$ ). (b) Optic microscope images of HepG2 cells after incubation in absence (control) and presence (catechol) of $1 \mathrm{mg} \mathrm{mL}^{-1} \mathrm{catechol}$ particles.

particles in HepG2 cells (values over 100\% should be considered as complete viability since these tests have an error around 10\%). Fig. 3 shows no significant differences between viability of liver hepatocellular carcinoma cell line (HepG2) by the XTT assay at increasing concentrations of catechol-based particles. Also optic microscope images of HepG2 cells after incubation in absence and presence of $1 \mathrm{mg} \mathrm{mL}{ }^{-1}$ catechol-based particles are shown to corroborate the absence of cytotoxic effects.

\section{Conclusions}

The conclusions obtained from this study are:

- The catechol-based particles can be used as adsorbents for the removal of low concentrations of cadmium and lead in water, although they did not present any affinity to chromium(vi).

- Activated carbon adsorbed all three heavy metals, but the catechol-based submicron particles resulted in adsorption capacities up to four times greater than those of AC with respect to cadmium and lead.

- The empirical modeling done in this work showed that the initial heavy metal concentration was the only statistically significant variable affecting adsorption capacity.

- Toxicity tests using catechol-based particles indicated no measurable toxicity neither via the use of Microtox assays nor in the case of human cells. Protein binding to catechol-based particles confers stability to the particles in physiological environments. Thus, this makes them cytocompatible and suitable for application in aquatic environments and other biological systems.

- Further research should be focused on the performance of catechol-based particles in multi-component systems including two or more heavy metals.

\section{Acknowledgements}

A. R. Contreras Rodríguez thanks the financial support through the scholarship provided by the Consejo Nacional de Ciencia y Tecnología (CONACYT, Mexico). D. Komilis is recipient of a scholarship from the TECNIOSPRING program (ACCIÓ, Generalitat de Catalunya). We also acknowledge financial support from MINECO (Project CTQ2010-15380/BQU) and MAT201238318-C03-02 from the Spanish Government and by FEDER funds. ICN2 acknowledges support from the Severo Ochoa Program (MINECO, Grant SEV-2013-0295). Authors also thank CM1101 and MP1106 Cost Actions.

\section{References}

1 F. Ge, M.-M. Li, H. Ye and B.-X. Zhao, Effective removal of heavy metal ions $\mathrm{Cd}(\mathrm{II}), \mathrm{Zn}$ (II), $\mathrm{Pb}$ (II), $\mathrm{Cu}$ (II) from aqueous solution by polymer-modified magnetic nanoparticles, $J$. Hazard. Mater., 2012, 211-212, 366-372.

2 G.-R. R. Bernardo, R.-M. J. Rene and A.-D. L. T. Ma Catalina, Chromium(III) uptake by agro-waste biosorbents: chemical characterization, sorption-desorption studies, and mechanism, J. Hazard. Mater., 2009, 170, 845-854.

$3 \mathrm{H}$. G. Gorchev and G. Ozolins, WHO guidelines for drinkingwater quality, WHO Chron., 1984, 38, 104-108.

4 K.-Y. Shin, J.-Y. Hong and J. Jang, Heavy metal ion adsorption behavior in nitrogen-doped magnetic carbon nanoparticles: isotherms and kinetic study, J. Hazard. Mater., 2011, 190, 36-44.

5 I. Mobasherpour, E. Salahi and M. Pazouki, Comparative of the removal of $\mathrm{Pb}$ (II), $\mathrm{Cd}(\mathrm{II})$ and $\mathrm{Ni}(\mathrm{II})$ by nano crystallite 
hydroxyapatite from aqueous solutions: adsorption isotherm study, Arabian J. Chem., 2012, 5, 439-446.

6 B. Benguella and H. Benaissa, Cadmium removal from aqueous solutions by chitin: kinetic and equilibrium studies, Water Res., 2002, 36, 2463-2474.

7 S. Recillas, A. García, E. González, E. Casals, V. Puntes, A. Sánchez and X. Font, Use of $\mathrm{CeO}_{2}, \mathrm{TiO}_{2}$ and $\mathrm{Fe}_{3} \mathrm{O}_{4}$ nanoparticles for the removal of lead from water, Desalination, 2011, 277, 213-220.

$8 \mathrm{~J} . \mathrm{Hu}, \mathrm{G}$. Chen and I. M. C. Lo, Removal and recovery of Cr(vI) from wastewater by maghemite nanoparticles, Water Res., 2005, 39, 4528-4536.

9 S. Recillas, J. Colón, E. Casals, E. González, V. Puntes, A. Sánchez and X. Font, Chromium VI adsorption on cerium oxide nanoparticles and morphology changes during the process, J. Hazard. Mater., 2010, 184, 425-431.

10 N. Savage and M. S. Diallo, Nanomaterials and Water Purification: Opportunities and Challenges, J. Nanopart. Res., 2005, 7, 331-342.

11 H. Lee, S. M. Dellatore, W. M. Miller and P. B. Messersmith, Mussel-inspired surface chemistry for multifunctional coatings, Science, 2007, 318, 426-430.

12 J. Sedó, J. Saiz-Poseu, F. Busqué and D. Ruiz-Molina, Catechol-based biomimetic functional materials, $A d v$. Mater., 2013, 25, 653-701.

13 Y. Liu, K. Ai and L. Lu, Polydopamine and its derivative materials: synthesis and promising applications in energy, environmental, and biomedical fields, Chem. Rev., 2014, 114, 5057-5115.

$14 \mathrm{M}$. $\mathrm{Hu}$ and B. Mi, Enabling graphene oxide nanosheets as water separation membranes, Environ. Sci. Technol., 2013, 47, 3715-3723.

15 H. Gao, Y. Sun, J. Zhou, R. Xu and H. Duan, Mussel-inspired synthesis of polydopamine-functionalized graphene hydrogel as reusable adsorbents for water purification, ACS Appl. Mater. Interfaces, 2013, 5, 425-432.

16 Z. Dong, D. Wang, X. Liu, X. Pei, L. Chen and J. Jin, Bioinspired surface-functionalization of graphene oxide for the adsorption of organic dyes and heavy metal ions with a superhigh capacity, J. Mater. Chem. A, 2014, 2, 5034-5040.

17 S. Zhang, Y. Zhang, G. Bi, J. Liu, Z. Wang, Q. Xu, H. Xu and X. Li, Mussel-inspired polydopamine biopolymer decorated with magnetic nanoparticles for multiple pollutants removal, J. Hazard. Mater., 2014, 270, 27-34.

18 Y. Yu, J. G. Shapter, R. Popelka-Filcoff, J. W. Bennett and A. V Ellis, Copper removal using bio-inspired polydopamine coated natural zeolites, J. Hazard. Mater., 2014, 273, 174-182.

19 N. Farnad, K. Farhadi and N. H. Voelcker, Polydopamine Nanoparticles as a New and Highly Selective Biosorbent for the Removal of Copper(II) Ions from Aqueous Solutions, Water, Air, Soil Pollut., 2012, 223, 3535-3544.

20 J. Saiz-Poseu, J. Sedó, B. García, C. Benaiges, T. Parella, R. Alibés, J. Hernando, F. Busqué and D. Ruiz-Molina, Versatile nanostructured materials via direct reaction of functionalized catechols, Adv. Mater., 2013, 25, 2066-2070.

21 A. R. Contreras, A. García, E. González, E. Casals, V. Puntes, A. Sánchez, X. Font and S. Recillas, Potential use of $\mathrm{CeO}_{2}$,
$\mathrm{TiO}_{2}$ and $\mathrm{Fe}_{3} \mathrm{O}_{4}$ nanoparticles for the removal of cadmium from water, Desalin. Water Treat., 2012, 41, 296-300.

22 D. C. Montgomery, Design and Analysis of Experiments, John Wiley \& Sons, Hoboken (USA), 8th edn, 2012, ch. 10.

23 R. Leardi, Experimental design in chemistry: A tutorial, Anal. Chim. Acta, 2009, 652, 161-172.

24 B. Dejaegher and Y. Vander Heyden, Experimental designs and their recent advances in set-up, data interpretation, and analytical applications, J. Pharm. Biomed. Anal., 2011, 56, 141-158.

25 G. E. P. Box, J. S. Hunter and W. G. Hunter. Statistics for Experimenters: Design, Innovation, and Discovery, Wiley, 2nd edn, 2005.

26 L. Brown and P. Mac Berthouex, Statistics for Environmental Engineers, CRC Press, 8th edn, 2002, ch. 38.

27 S. Parvez, C. Venkataraman and S. Mukherji, A review on advantages of implementing luminescence inhibition test (Vibrio fischeri) for acute toxicity prediction of chemicals, Environ. Int., 2006, 32, 265-268.

28 A. Garcia, S. Recillas, A. Sánchez and X. Font, The Luminescent Bacteria Test to Determine the Acute Toxicity of Nanoparticle Suspensions, in Nanotoxicity Methods and Protocols, 2012, vol. 926, pp. 255-259.

29 R. Barrena, E. Casals, J. Colón, X. Font, A. Sánchez and V. Puntes, Evaluation of the ecotoxicity of model nanoparticles, Chemosphere, 2009, 75, 850-857.

30 A. H. Cory, T. C. Owen, J. A. Barltrop and J. G. Cory, Use of an aqueous soluble tetrazolium/formazan assay for cell growth assays in culture, Cancer Commun., 1991, 3, 207-212.

31 C. You, C. Han, X. Wang, Y. Zheng, Q. Li, X. Hu and H. Sun, The progress of silver nanoparticles in the antibacterial mechanism, clinical application and cytotoxicity, Mol. Biol. Rep., 2012, 39, 9193-9201.

32 D. Singh and N. S. Rawat, Sorption of $\mathrm{Pb}(\mathrm{II})$ by bituminous coal, Indian J. Chem. Technol., 1995, 2, 49-50.

33 A. L. Degodo, C. Perez and F. A. Copez, Sorption of heavy metals on blast furnace sludge, Indian J. Chem. Technol., 1998, 32, 1989-19964.

34 M. A. Ferro-Gracia, R. J. Utrilla and B. I. Toledo, Adsorption of zinc, cadmium and copper on activated carbons obtained from agricultural by-products, Carbon, 1988, 26, 263-273.

35 C. P. Huang, The removal of chromium(vi) from diluted aqueous solution by activated carbon, Water Res., 1977, 11, 673-679.

36 R. Leyva-Ramos, J. Rangel-Mendez, J. Mendoza-Barron, L. Fuentes-Rubio and R. Guerrero-Coronado, Adsorption of cadmium(II) from aqueous solution onto activated carbon, Water Sci. Technol., 1997, 35, 205-211.

37 A. K. Bhattacharya and C. Venkobachar, Removal of Cadmium(II) by Low Cost Adsorbents, J. Environ. Eng., 1984, 110, 110-122.

38 A. Netzer, Adsorption of copper, lead and cobalt by activated carbon, Water Res., 1984, 18, 927-933.

39 K. Kadirvelu and C. Namasivayam, Activated carbon from coconut coirpith as metal adsorbent: adsorption of $\mathrm{Cd}(\mathrm{II})$ from aqueous solution, Adv. Environ. Res., 2003, 7, 471-478. 
40 M. Pérez-Candela, J. Martín-Martínez and R. TorregrosaMaciá, Chromium(vi) removal with activated carbons, Water Res., 1995, 29, 2174-2180.

41 D. Mohan and C. U. Pittman, Activated carbons and low cost adsorbents for remediation of tri- and hexavalent chromium from water, J. Hazard. Mater., 2006, 137, 762-811.

42 M. Ferrero-García, J. Rivera-Ultrilla, J. Rodríguez-Gordillo and I. Bautista-Toledo, Adsorption of zinc, cadmium, and copper on activated carbons obtained from agricultural byproducts, Carbon, 1988, 26, 363-373.

43 M. Kobya, E. Demirbas, E. Senturk and M. Ince, Adsorption of heavy metal ions from aqueous solutions by activated carbon prepared from apricot stone, Bioresour. Technol., 2005, 96, 1518-1521.

44 A. R. Contreras, E. Casals, V. Puntes, D. Komilis, A. Sánchez and $\mathrm{X}$. Font, Use of cerium oxide $\left(\mathrm{CeO}_{2}\right)$ nanoparticles for the adsorption of dissolved cadmium(II), lead(II) and chromium(vi) at two different pHs in single and multicomponent systems, Global NEST J., 2015, 17, 536-543.
45 M. Amini, H. Younesi, N. Bahramifar, A. A. Z. Lorestani, F. Ghorbani and A. Daneshi, Application of response surface methodology for optimization of lead biosorption in an aqueous solution by Aspergillus niger, J. Hazard. Mater., 2008, 154, 694-702.

46 R. E. Olson and D. D. Christ, Chapter 33. Plasma Protein Binding of Drugs, Annu. Rep. Med. Chem., 1996, 31, 327-336.

47 L. A. Sklar, B. S. Hudson and R. D. Simonir, Conjugated Polyene Fatty Acids as Fluorescent Probes: Binding to Bovine Serum Albumin, Biochemistry, 1977, 16, 5100-5108.

48 C. A. Royer, Probing protein folding and conformational transitions with fluorescence, Chem. Rev., 2006, 106, 17691784 .

49 A. Sánchez, S. Recillas, X. Font, E. Casals, E. González and V. Puntes, Ecotoxicity of, and remediation with, engineered inorganic nanoparticles in the environment, TrAC, Trends Anal. Chem., 2011, 30, 507-516. 